\title{
Drilling Vessel Chikyu: Status, Capabilities, and Current Operations
}

\author{
By Daniel Curewitz, Shin'ichi Kuramoto, and Yoshi Kawamura
}

\section{Background and History}

The Deep Sea Drilling Vessel Chikyu is a state-of-the-art drilling platform that can reach geological targets previously inaccessible to scientific drilling. This 210-m-long, 57,000-ton vessel comes equipped with a $121-\mathrm{m}$-tall drilling derrick, a fully integrated riser drilling system and blow-out preventer (BOP), and a highly automated drill floor system that runs efficiently and safely with a small number of operating personnel. The Chikyu is flexible enough to allow both riser and riserless operations, depending on the scientific and technical requirements of a given expedition.

Construction of the Chikyu finished in July 2005 in Nagasaki, Japan, and the ship set sail in early August 2005 (Taira, 2005). Basic operational tests, vessel operation training, and safety protocol and procedure training were conducted off Nagasaki, in Suruga Bay, and off the Boso Peninsula, Japan. Several open-house events were scheduled around Japan during this period, and more than 25,000 visitors gained a first-hand view of the Chikyu's scientific capabilities. In October 2005, full-scale test operations were conducted off the Shimokita Peninsula between Honshu and Hokkaido, Japan (Fig. 1). These operations were designed to

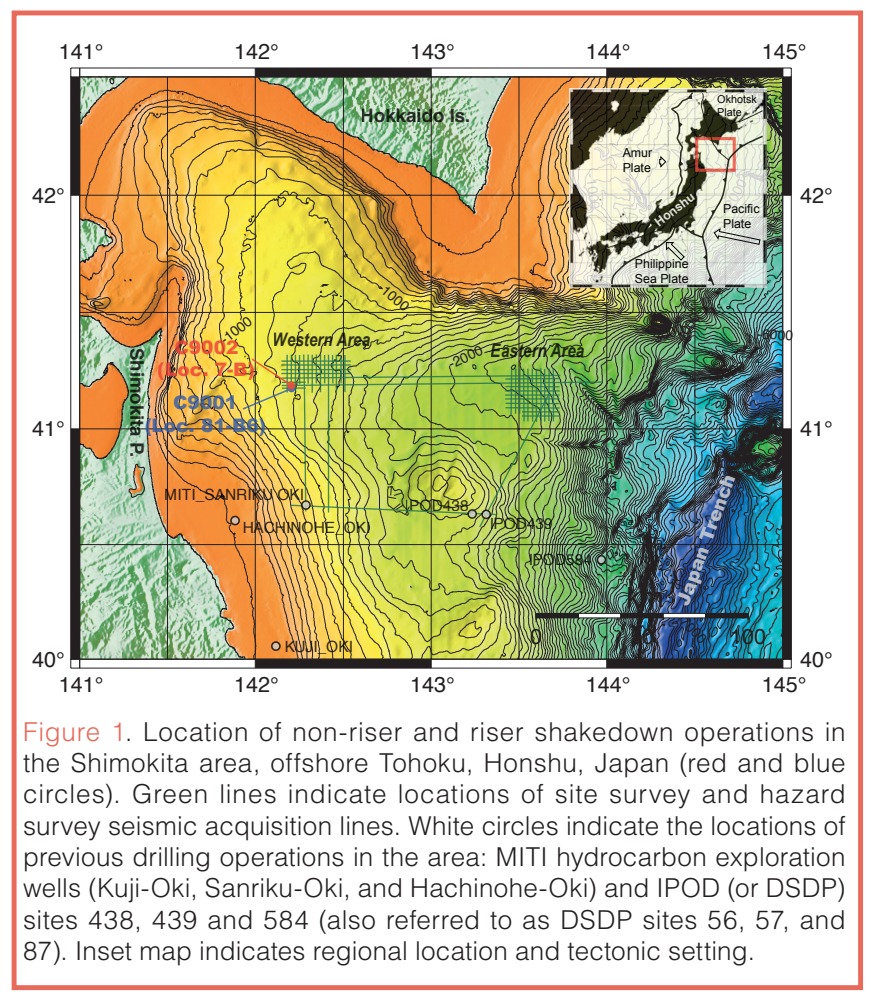

train the vessel operators, scientists, navigators, and drilling and technical crew; to troubleshoot and modify the drilling, coring, and laboratory systems; and to provide a basis for further development and integration of the wide array of systems onboard the vessel. The first tests comprised riserless drilling operations and a series of hydraulic piston coring (HPC) operations designed to evaluate the basic operational capabilities of the system.

\section{First Shimokita Shakedown: Riserless Drilling Tests}

System integration and operational testing and training procedures conducted offshore of northern Honshu in October 2005 focused on pipe handling, drill-string construction, ship positioning, riserless drilling, and hydraulic piston coring. Additional operations focused on core handling, curation, description, and measurement using the onboard laboratory facilities.

Drilling tests included the full use of the pipe-handling and drill-string assembly system. Drill pipe was delivered to the fingerboard (the pipe-section deployment rack, Fig. 2) using the deck cranes, pipe racker, and pipe transfer system. The iron roughneck and the power swivel were used to position and attach successive drill-pipe sections to the drill string, and the entire assembled drill string, with drill bit and HPC assembly attached, was lowered to the seafloor. All pipe assembly and drilling operations were controlled from the drillers' house on the rig floor, and drilling was conducted via the top-drive assembly attached to the derrick. Coring operations were conducted by lowering core sleeves through the drill string to the bit and by collecting core through actuating the HPC system. Cores were retrieved with the coreline winch and delivered to the core receiving area. Throughout the operation, position was maintained and monitored from the drillers' control area and the bridge using the dynamic position system to control the vessel's six $360^{\circ}$ azimuth thrusters and one fixed bow thruster. Approximately $120 \mathrm{~m}$ of core was retrieved from two sites during this testing operation.

Laboratory operations began with receiving, labeling, measuring, and marking of cores, entry of core data into the J-CORES database, headspace gas monitoring for safety, sampling for microbiological research, and cutting of cores into sections. Core sections were transported to the core 
laboratory for x-ray computer tomography scanning, wholecore multi-sensor core logging (MSCL), QA/QC analysis for pore fluids and gas, and further microbiological sampling. Core sections were then split lengthwise into working and archive halves. Archive halves were subjected to nondestructive measurements and analyses, including smearslide studies for sedimentological and micropaleontological analysis, color spectrum and image scanning, split-core MSCL, and x-ray fluorescence scanning. Working halves were used for visual core description, and sub-samples were collected for analysis of density, porosity, velocity, sedimentology, paleontology, paleomagnetism, and petrography. Paleomagnetic analyses of whole cores were conducted in the laboratory's shielded magnetic-field-free room in February 2006. All data collected via this array of laboratory procedures were entered and stored in the onboard J-CORES database, which was used for display and presentation of data and initial interpretations.

\section{Upcoming Tests, New Equipment, and Upgraded Capabilities}

From August to October 2006, a full riser drilling operational test will take place in the same area as the initial riserless drilling shakedown operations, in water depths of $1000 \mathrm{~m}$ (Fig. 1). These tests will incorporate every aspect of riser and riserless drilling, coring, logging, casing, and hole completion. Riserless drilling will be used to establish pilot holes and the initial borehole required for installing the casing, wellhead, and BOP (Fig. 2). The newly installed, remotely operated vehicle (ROV) will be used to help install, observe, and manipulate the seafloor assemblies, as well as monitor safety and operational parameters during drilling. Riser pipe will be run from the ship to the BOP on the seafloor, and riser drilling with HPC and rotary coring facilita-

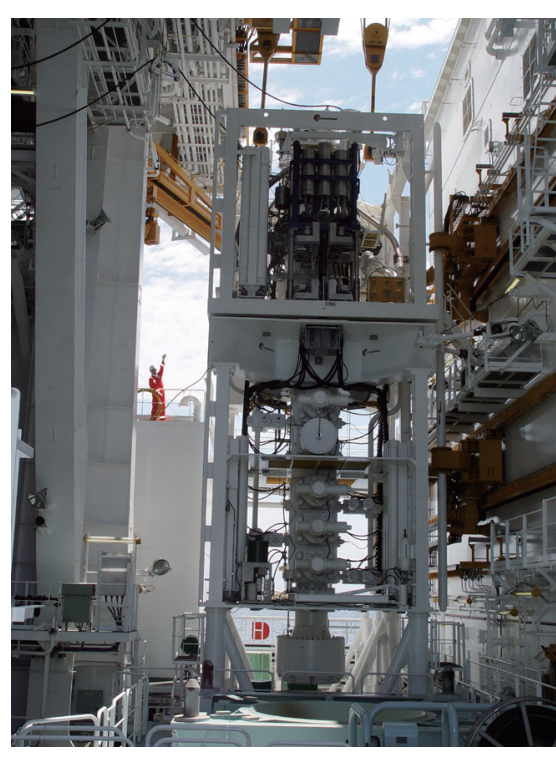

Figure 2. External view of Chikyu's blow out preventer (BOP). BOP hangs from riser pipe attached to high-powered winches on ship's derrick and will be deployed onto seafloor through moonpool below drilling platform Note person on left for scale. approximately 6-7 month period of riser drilling organized by JAMSTEC/ CDEX through a collaborative effort with industry. The borehole data from these operations, likely to take place as far away as the western Indian Ocean, will be proprietary to the industry group that finances them; however, the opera-

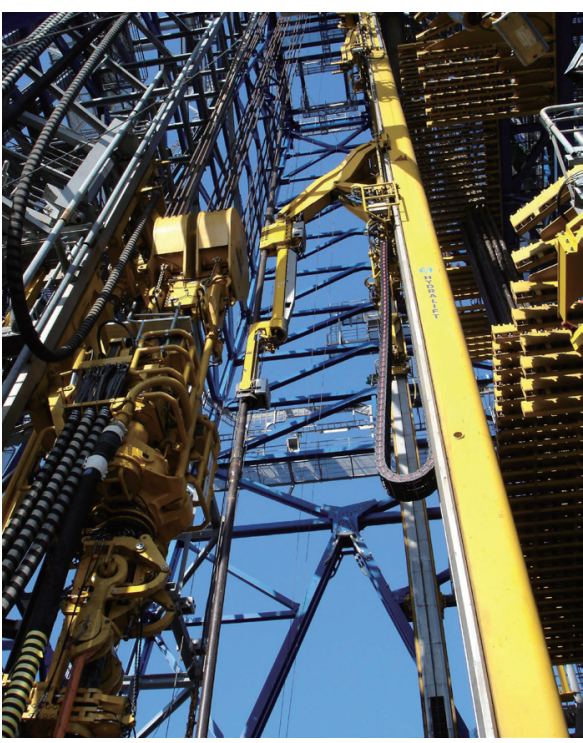

Figure 3. High powered top drive and pipe handling system, setting a 4-stand drilling pipe to the pipe racker. tional experience

gained from the drilling activities will be shared with onboard CDEX personnel and will help in further testing and development of the riser-drilling capability of the platform.

All of these preparations and tests are focused on readying the entire operation for the start of IODP operations in September 2007, when the D/V Chikyu is scheduled to begin drilling operations in the Kumano Basin area of the Nankai Trough, all as an integral component of the NanTroSEIZE project (Tobin and Kinoshita, 2006).

\section{References}

Taira, A., 2005. The Chikyu: Meeting the challenges of a new scientific drilling era. Scientific Drilling, 1,32-33.

Tobin, H. J., and Kinoshita, M., 2006. NanTroSEIZE: The IODP Nankai Trough seismogenic zone experiment. Scientific Drilling, 2:23-27.

\section{Authors}

Daniel Curewitz, Shin'ichi Kuramoto and Yoshi Kawamura, Center for Deep Earth Exploration (CDEX), JAMSTEC, Yokohama Institute for Earth Science, 3173-25 Showa-machi, Kanazawa-ku, Yokohama 236-0001, Japan, e-mail: daniel@jamstec.go.jp

\section{Figure Credits}

Photos courtesy of Japan Agency of Marine-Earth Science and Technology (JAMSTEC)

Following completion of the drilling and laboratory tests off Shimokita Peninsula in the fall of 2006, D/V Chikyu will embark on an

\section{Related Web Link}

http://www.jamstec.go.jp/chikyu/jp/index.html 